\title{
Wheal Size
}

National Cancer Institute

\section{Source}

National Cancer Institute. Wheal Size. NCI Thesaurus. Code C112429.

The size of the flat, circular, slightly raised area that forms around the site of an antigenic challenge to the skin. 